\title{
Megaloblastic anemia in children: Case series from a single institution and literature review
}

\author{
Andreea Oltean', Mihaela Ioana Chincesan², Maria Despina Baghiu', Eniko Molnar ${ }^{3}$, \\ Cristina Oana Marginean ${ }^{2}$ \\ ${ }^{1}$ Pediatric Clinic I, Mures County Emergency Hospital, Tg. Mures, Romania \\ ${ }^{2}$ Pediatric Clinic I, University of Medicine, \\ Pharmacy, Science and Technology, Tg. Mures, Romania \\ ${ }^{3}$ Laboratory Department, Mures County Emergency Hospital, Tg. Mures, Romania
}

\begin{abstract}
Folic acid and cobalamin are B-group vitamins that play an essential role in many cellular processes. Deficiency in one or both of these vitamins causes megaloblastic anemia, a very rare anemia in children, which is characterized by the presence of megaloblasts. Vitamin $\mathrm{B}_{12}$ deficiency can be caused by a low intake, decreased absorption, or impaired use.

We present five cases of megaloblastic anemia that illustrate the onset of anemia at different ages and in different pathologies.

We concluded that megaloblastic anemia is a rare anemia diagnosed in children, with multiple causes, occurring in the context of a vegetarian diet, or associated with an autoimmune disease, protein-calorie malnutrition of the mother during pregnancy and megaloblastic anemia of the mother associated with lack of substitution during pregnancy and during breastfeeding.
\end{abstract}

Keywords: megaloblastic anemia, megaloblasts, vitamin $B_{12}$, folic acid

\begin{abstract}
Abbreviations
$\mathrm{Hgb}-$ Hemoglobin

$\mathrm{MCHC}$ - mean corpuscular hemoglobin concentration

$\mathrm{MCV}$ - mean corpuscular volume
\end{abstract}

\section{INTRODUCTION}

Megaloblastic anemia is a macrocytic anemia caused by deficiency of cobalamin, folate, or both (1). The average age of occurrence is 60 years; it is rare in children, except in underdeveloped countries, where due to the socio-economic situation and the lack of vitamin $B_{12}$ in food, it is more common. It is also commonly associated with autoimmune diseases (2). Vitamin $\mathrm{B}_{12}$ is a water-soluble vitamin and plays a major role in metabolic reactions. People are totally dependent on vitamin $\mathrm{B}_{12}$ from the diet. Food sources of vitamin $\mathrm{B}_{12}$ are almost exclusively of animal sources (3).

Vitamin $\mathrm{B}_{12}$ deficiency can occur in breastfed infants by vegetarian mothers or with megaloblas- tic anemia; it can also be caused by intestinal malabsorption in Crohn's disease, celiac disease, chronic pancreatitis, Diphyllobothrium latum infestation or after resection of the terminal ileum $(1,4)$. Malabsorption of vitamin $\mathrm{B}_{12}$ caused by intrinsic factor deficiency is very rare in children. Folic acid deficiency is also caused by poor nutrition, malabsorption or increased needs.

Megaloblastic anemia is an anemia that is characterized by the presence of precursor cells, megaloblast in the bone marrow and macrocytic red cells in the peripheral blood. These megaloblasts arise because of impaired DNA synthesis followed by ineffective erythropoiesis. Other changes include low hemoglobin and erythrocyte count, elevated mean corpuscular volume $(\mathrm{MCV}>100 \mathrm{fL})$, in- 
creased mean corpuscular hemoglobin concentration (MCHC), thrombocytopenia, low reticulocyte count. A low serum vitamin B12 (VN $=191-663$ $\mathrm{pg} / \mathrm{ml})$ or folic acid $(\mathrm{VN}=4.6-18.7 \mathrm{ng} / \mathrm{ml})$ supports the positive diagnosis (5).

Depending on the type of deficiency, vitamin $\mathrm{B}_{12}$ substitution treatment consists initially in one intramuscular loading dose each week for 1 month, then a maintenance dose or taking folic acid orally to correct anemia and megaloblastosis (6).

We report four cases of megaloblastic anemia, diagnosed in a Tertiary Hospital of Pediatrics, Emergency Hospital Tg. Mures, Romania between 2015-2018.

The informed consent was obtained from the patients' mothers (legal guardians) for publication of these cases.

\section{CASE SERIES}

\section{Case 1}

15 year old female patient, with predominantly vegetarian diet, was hospitalized for fatigability at small/moderate effort and paleness, a hematological malignancy being initially suspected. Clinical examination is showed in Table 1 and her laboratory findings confirmed severe vitamin $\mathrm{B}_{12}$ deficiency, as seen in Table 2. Peripheral smear and bone marrow are described in Table 3, characteristics of bone marrow are shown in Figure 1. Red cell transfusion was initiated, subsequently vitamin $\mathrm{B}_{12}$ intramuscular for 5 days, evolution being favorable. The case was interpreted as a megaloblastic anemia due to nutrition mistakes.

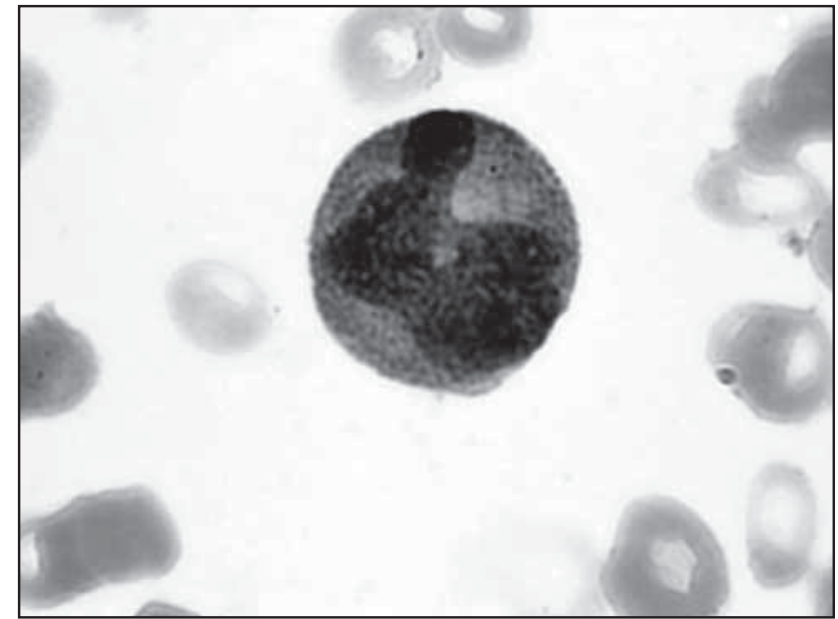

FIGURE 1. Bone marrow aspiration showing hypercellularity with giant metamyelocytes

\section{Case 2}

Infant male, age four months, was hospitalized for accentuated pallor of skin and mucosa. Family history showed that during the pregnancy the mother was diagnosed with mixed iron deficiency anemia and vitamin $B_{12}$ and folic acid deficiency, having a strict vegetarian diet. The infant's history reveals a physiological term birth, born naturally, birth weight 3,000 g, Apgar score 9/1 min, exclusively breastfed until present, vaccinated, at 4 months diagnosed with hypotonic syndrome. Clinical examination is showed in Table 1 and laboratory studies are shown in Table 2 and Table 3, confirming severe anemia due to vitamin $B_{12}$ deficiency. The aspect of bone marrow is shown in Figure 2. Hemoglobin electrophoresis was performed: $\mathrm{Hgb}$ A $89.8 \% \mathrm{Hgb} \mathrm{A}_{2} 4.6 \%$, Hgb F 5.6\%. Red blood cells and platelet transfusion was initiated, vitamin $\mathrm{B}_{12}$ intramuscularly. The case was interpreted as a megaloblastic anemia and beta - thalassemia minor.

TABLE 1. Clinical findings of case reports

\begin{tabular}{|l|l|l|l|l|l|}
\hline & Case 1 & Case 2 & Case 3 & Case 4 & Case 5 \\
\hline Age & 15 years & 4 months & 6 months & 11 years & 8 months \\
\hline Sex & F & M & F & F & F \\
\hline General state & fa gability, poor appe te & poor appe te & $\begin{array}{l}\text { poor appe te, PI <0.6 } \\
\text { (dystrophy grade III) }\end{array}$ & $\begin{array}{l}\text { good } \\
\text { (dystrophy grade II) }\end{array}$ \\
\hline Skin tone & pallor, sallow tone & $\begin{array}{l}\text { pallor, mild } \\
\text { jaudince }\end{array}$ & $\begin{array}{l}\text { marked pallor, facial edema, } \\
\text { decreased turgor }\end{array}$ & pallor & pallor \\
\hline $\begin{array}{l}\text { Mucosal } \\
\text { abnormali es }\end{array}$ & $\begin{array}{l}\text { paleness, depapillated } \\
\text { smooth, red tongue, mild } \\
\text { gingival hypertrophy }\end{array}$ & pallor & pallor, conjunc val edema & $\begin{array}{l}\text { candidiasis, } \\
\text { commisural } \\
\text { rhagades }\end{array}$ & pallor \\
\hline $\begin{array}{l}\text { Muscle tone } \\
\text { normal }\end{array}$ & hypotony & generalized muscle weakness & normal & mild hypotony \\
\hline $\begin{array}{l}\text { Osteoar cular } \\
\text { abnormali es }\end{array}$ & normal & normal & $\begin{array}{l}\text { rickety chest, AF =2/1cm, } \\
\text { depressed }\end{array}$ & normal & normal \\
\hline Splenomegaly & No & Yes & No & No & No \\
\hline Stool & normal & normal & Chronic diarrhea & normal & stool with mucus \\
\hline PI = ponderal index, AF = anterior fontanele & &
\end{tabular}


TABLE 2. Laboratory indings of case reports

\begin{tabular}{|l|c|c|c|c|c|}
\hline & Case 1 & Case 2 & Case 3 & Case 4 & Case 5 \\
\hline Hgb $(\mathrm{g} / \mathrm{dl})$ & 5.6 & 4.9 & 6.8 & 11.4 & 6.9 \\
\hline $\mathrm{MCV}(\mathrm{fL})$ & 97.7 & 73.7 & 97.5 & 107.0 & 98.1 \\
\hline $\mathrm{MCHC}(\mathrm{g} / \mathrm{dl})$ & 35.0 & 37.6 & 37.2 & 33.8 & 31.4 \\
\hline Leucocites $\left(/ \mathrm{mm}^{3}\right)$ & 4,900 & 7,000 & 3,900 & 6,200 & 5,260 \\
\hline Platelets $\left(/ \mathrm{mm}^{3}\right)$ & 132,000 & 56,000 & 88,000 & 68,000 & 131,000 \\
\hline Re culocites $(\%)$ & 12 & 8 & 6 & 30 & 10 \\
\hline Vitamin $\mathrm{B}_{12}(\mathrm{pg} / \mathrm{ml})$ & 33 & $<50$ & - & 56 & 91 \\
\hline Homocistein $(\mu \mathrm{mol} / \mathrm{l})$ & 51.91 & - & - & - & - \\
\hline
\end{tabular}

TABLE 3. Characteristics of peripheral smear and bone marrow of case reports

\begin{tabular}{|l|c|c|c|c|c|}
\hline Peripheral smear & Case 1 & Case 2 & Case 3 & Case 4 & Case 5 \\
\hline Macro-ovalocytes & + & + & + & + & + \\
\hline Anisocytosis & + & + & + & - & + \\
\hline Poikilocytosis & - & + & + & - & - \\
\hline Erythrocytes with Cabot rings & + & + & - & - & - \\
\hline Howell-Jolly bodies & + & + & - & - & + \\
\hline Macrothrombocytes & + & + & - & + & - \\
\hline Hypersegmented neutrophils & + & - & - & + & - \\
\hline Bone marrow & \multicolumn{7}{|l|}{} & + & \multicolumn{2}{|c|}{} \\
\hline Erythroid hyperplasia & + & + & - & + & + \\
\hline Giant metamielocytes & + & + & + & + & + \\
\hline Megaloblastosis & + & + & + & + & + \\
\hline Howell-Jolly bodies & + & + & - & + & + \\
\hline Hypersegmented neutrophils & + & - & + & + & - \\
\hline
\end{tabular}

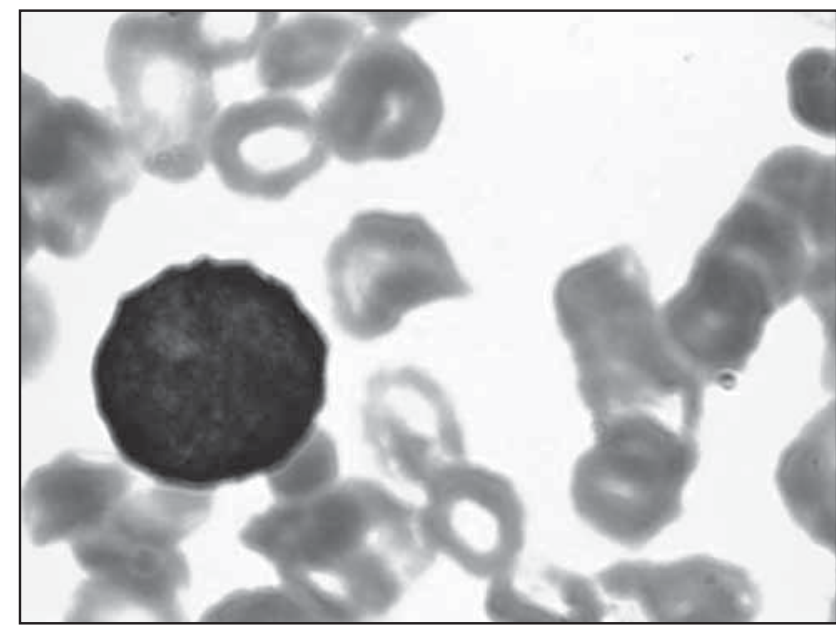

FIGURE 2. Bone marrow aspiration showing erythroblastic series with moderate hyperplasia with megaloblasts

\section{Case 3}

Female infant, age 6 months, hospitalized for capricious appetite, downward weight curve, semi consistent stools, marked paleness of skin and mu- cosa. From personal history we retain physiological term birth, Apgar score 10/1 min, birth weight 3,200 g, breastfed exclusively for a month, later with goat milk, vaccinated, non-diversified, admitted to the Pediatric Clinic at age 2 months with bronchiolitis.

Clinical examination is showed in Table 1 and her laboratory abnormalities are shown in Table 2. Peripheral smear and bone marrow are described in Table 3, confirming megaloblastic anemia. Bone marrow aspect is shown in Figure 3. Folic acid was administered orally and vitamin $B_{12}$ mcg intramuscularly, although folate and vitamin $\mathrm{B}_{12}$ dosing was not conducted for objective reasons, due to low compliance and because the mother was discharged upon request. Mother was also counseled about the diet modification. In this case, megaloblastic anemia is interpreted in the context of protein-calorie malnutrition, multiple food mistakes and poor socio-economic conditions. 


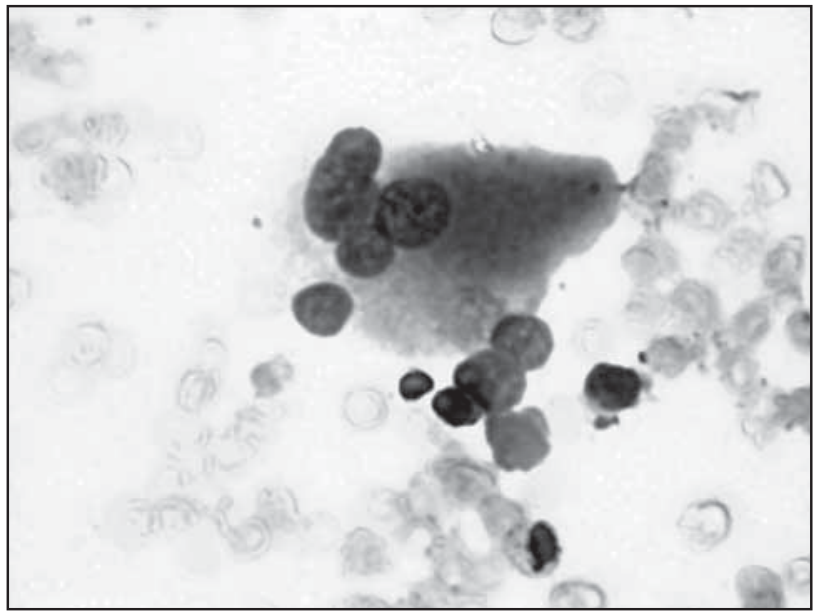

FIGURE 3. Bone marrow aspiration showing megakaryocytes with nucleus explosion

\section{Case 4}

11 years old female, diagnosed at age 6 weeks with mucocutaneous candidiasis, and after the age of 10 with autoimmune type I poliendocrinopaty, during multiple endocrinology assessments, patient presents thrombocytopenia, which is why she was hospitalized for hematological evaluation. Personal pathological history: mucocutaneous candidiasis, hypoparathyroidism, primary adrenal insufficiency. Clinical examination abnormalities are showed in Table 1 and laboratory studies are shown in Table 2 and Table 3, confirming megaloblastic anemia. Peripheral smear aspect is shown in Figure 4. Substitution treatment was initiated with vitamin $\mathrm{B}_{12}$ intramuscularly. In this case, megaloblastic anemia was interpreted as part of the autoimmune poliendocrinopaty complex.

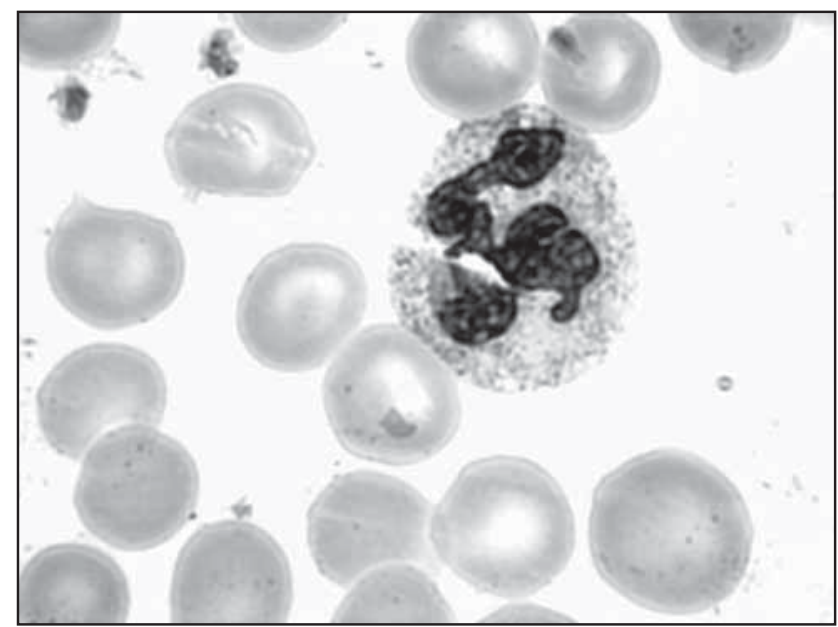

FIGURE 4. Peripheral smear showing macrocytosis and hypersegmented neutrophils

\section{Case 5}

8-month-old female infant with mother known with megaloblastic anemia was admitted for poor appetite and slow weighing curve, with no apparent pathological history. Clinical examination abnormalities are presented in Table I, and laboratory investigations are presented in Table 2 and Table 3, confirming megaloblastic anemia. The appearance of the peripheral smear is shown in Figure 5. Substitution treatment was initiated with red blood cells, followed by vitamin $\mathrm{B}_{12}$ intramuscular. This case was interpreted as a megaloblastic anemia in an infant whose mother was diagnosed with megaloblastic anemia and had prompt response to vitamin $\mathrm{B}_{12}$ substitution.

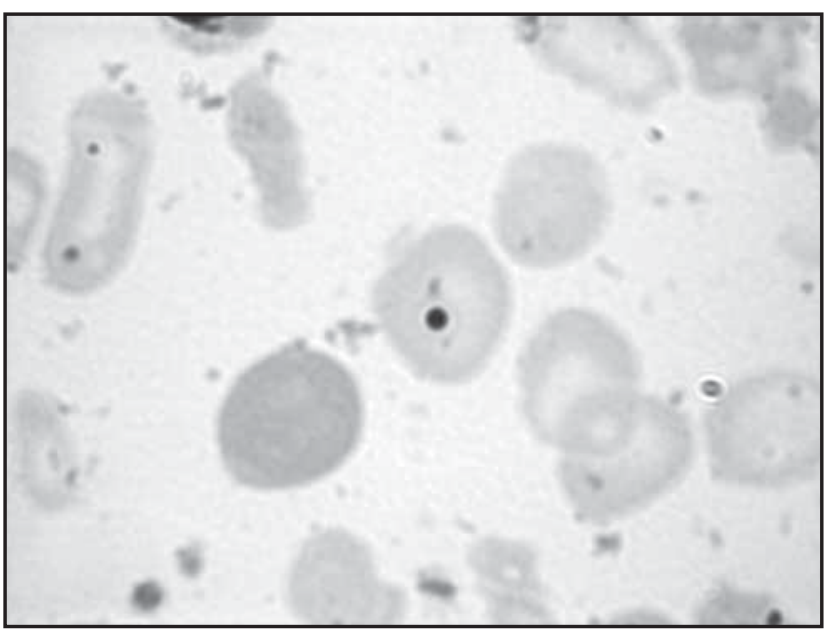

FIGURE 5. Peripheral blood smear showing erythrocytes with Howell-Jolly bodies

\section{DISCUSSIONS}

Megaloblastic anemia frequency varies according to geographical regions, being much higher in the Netherlands, Scandinavian countries, USA, Canada versus Southern and Eastern Europe where it is very low; however, it is not excluded that this anemia is widespread compared to the data, and that probably not all the cases are diagnosed (6). Due to folate deficiency, megaloblastic anemia is frequently attested in underdeveloped countries with a low quality of life and insufficient nutrition (7).

Infants with megaloblastic anemia may have skin paleness, moderate jaundice, can be more irritable, with capricious appetite, while older children may complain of numbness and weakness; these symptoms have been described in the five cases presented, which are similar to many reported studies $(8-10)$.

Megaloblastic anemia is an important cause of cytopenias. The initial workup are a blood count and a peripheral smear (11); revealing: a low value of hemoglobin and red blood cell count, increased 
MCV (> $100 \mathrm{fL}$ ), normal mean corpuscular hemoglobin concentration (MCHC), thrombocytopenia, decreased number of reticulocytes, peripheral smear with macro-ovalocytes, anisocytosis, poikilocytosis, red blood cells with Cabot rings, HowellJolly bodies, large platelets, hypersegmented neutrophils $(1,2,4)$.

Sometimes signs of hemolysis are detected with increased value of lactic acid dehydrogenase and indirect bilirubin, that can be attributed to intramedullary destruction of red blood cells (12). Bone marrow smear reveals erythroid hyperplasia, giant metamielocytes, megaloblastosis, Howell-Jolly bodies, hypersegmented neutrophils (6). Low serum levels of vitamin $B_{12}$ and folic acid sustain the diagnosis.

The five cases presented illustrate the onset of megaloblastic anemia at different ages and in different pathologies. Thus, the first two patients have the onset of the disease at 14 years and 4 months respectively, with pale skin and fatigue. Laboratory evaluation in both cases reveal a severe anemia and thrombocytopenia, blood smear with macrocytosis, and the bone marrow aspect pleading for megaloblastic anemia, vitamin $\mathrm{B}_{12}$ deficiency confirmed by dosing. In the first case, megaloblastic anemia was due to predominantly vegetarian food. Ravikumar et al. reported that in a group of 40 adolescents with megaloblastic anemia, $82.5 \%$ had vegetarian or a predominantly vegetarian diet pattern (9). Suarez $\mathrm{T}$ et al. have reported iron, folic acid and vitamin $\mathrm{B}_{12}$ deficiencies in $34.6 \%, 90.9 \%$ and $18.1 \%$ respectively of the anemic adolescents aged 12-19 years (13). Food fortification with folic acid, vita$\min \mathrm{B}_{12}$ and other micronutrients is a low cost and could be an effective measure to control anemia in high-risk populations. The 4 month old baby was fed only naturally, the cause of vitamin $\mathrm{B}_{12}$ deficiency being the strictly vegetarian diet of the mother during pregnancy and later, accompanied by lack of vitamin supplementation. Megaloblastic anemia due to vitamin $\mathrm{B}_{12}$ deficiency in exclusively breastfed infants born to vegan mothers has been reported by other authors and it is an important cause of neuromotor retardation (14-18). Performing hemoglobin electrophoresis, this patient also had an associated minor beta-thalassemia, which masked the macrocytosis and thus explained the lower value of MCV (73.7 fL). The fifth patient also falls into the category of megaloblastic anemia caused by the lack of vitamin supplementation, but in the context of a maternal megaloblastic anemia.

The next two patients were diagnosed by chance with megaloblastic anemia, in the context of asso- ciated pathology. Thus, the $3 \mathrm{rd}$ patient is diagnosed with malabsorption syndrome, IIIrd degree dystrophy, food mistakes, and peripheral smear with aspect of megaloblastic anemia, raised the suspicion, confirmed by bone marrow aspirate. In an Indian study, conducted on a sample of 29 infants with megaloblastic anemia, protein-calorie malnutrition has been documented in 14 cases. Vitamin $\mathrm{B}_{12}$ and folic acid dosage was done in only 10 cases, showing either a combined deficit of vitamin $\mathrm{B}_{12}$ and folate deficiency or only isolated vitamin $\mathrm{B}_{12}$ or folic acid deficiency. In the remaining patients the diagnosis of megaloblastic anemia was stated on peripheral smear and bone marrow appearance (19).

Case 4 represents an 11 year old patient diagnosed with autoimmune type I poliendocrinopaty, with associated and unexplained thrombocytopenia, which leads us to carry out investigations such as blood and marrow examination and eventually the dosage of vitamin $\mathrm{B}_{12}$, which confirms the diagnosis. The literature reminds us that autoimmune diseases can be a trigger of megaloblastic anemia. There were reported cases of megaloblastic anemia associated with autoimmune hemolytic anemia, rheumatoid arthritis or autoimmune thyroiditis, Sjögren's syndrome and systemic lupus erythematosus (20-22).

Megaloblastic anemia is generally suspected in children having anemia with raised $\mathrm{MCV}$ and should be strongly suspected in all children having bicytopenia or pancytopenia (23). This case series described the varied presentations of the megaloblastic anemia in children and in different pathologies.

\section{CONCLUSIONS}

Megaloblastic anemia is a rarely diagnosed anemia in children, probably under diagnosed, with multiple causes, occurring in the context of a vegetarian diet, or associated with an autoimmune disease, poor socio-economic conditions, protein-calorie malnutrition, vegetarian nutrition of the mother during pregnancy associated with lack of substitution during pregnancy and during breastfeeding and last but not least maternal megaloblastic anemia.

Supplementation with vitamin $\mathrm{B}_{12}$ should be offered to all mothers during pregnancy and postnatal during breastfeeding beside iron and folic acid substitution, especially if the mother is vegetarian or comes from low socio-economic conditions. 


\section{REFERENCES}

1. William W. Hematologic Disorders In: Pediatrics Current Diagnosis and Treatment. 21th ed. New York: McGraw-Hill Lange; 2012:904905.

2. Kaferle J, Strzoda CE. Evaluation of macrocytosis. Am Fam Physician. 2009;79(3):203-208.

3. Antony AC. Megaloblastic anemias. In: Basic Principles and Practice. Philadelphia, Elsevier Churchill Livingstone; 2008:390-395.

4. Hoffbrand AV. Megaloblastic Anemias. Harrison's Principles of Internal Medicine. In: 18th ed. New York; 2012:903-905.

5. Jan AZ, Gul Z, Liaqat F. Megaloblastic anemia and pattern of its presentation in children. Gomal J Med Sci. 2016;14(2).

6. Aslinia F, Mazza JJ, Yale SH. Megaloblastic anemia and other causes of macrocytosis. Clin Med Res. 2006;4(3):236-241.

7. Galloway M, Hamilton M. Macrocytosis: Pitfalls in testing and summary of guidance. BMJ. 2007;335(7625):884-886.

8. Yellinedi S, Karanam S, Gowdar G. Clinico-hematologic profile of megaloblastic anemia in children. Int $\mathrm{J}$ Contemp Pediatr. 2016;3(1):28-30.

9. Ravikumar N, Amaresh A, Anita S. Study of Etiology and Varied Clinical Features of Megaloblastic Anemia in Adolescents at Niloufer Hospital. IOSR J Dent Med Sci. 2016;15(1):16-20.

10. Zengin E, Sarper N, Caki Kiliç S. Clinical manifestations of infants with nutritional vitamin $\mathrm{B}$ deficiency due to maternal dietary deficiency. Acta Paediatr Oslo Nor 1992. 2009;98(1):98-102.

11. Janus J, Moerschel SK. Evaluation of anemia in children. Am Fam Physician. 2010;81(12):1462-1471.

12. Castellanos-Sinco HB, Ramos-Peñafiel $C O$, Santoyo-Sánchez A et al. Megaloblastic anaemia: Folic acid and vitamin B12 metabolism. Rev Médica Hosp Gen México. 2015;78(3):135-143.

13. Suárez T, Torrealba M, Villegas $\mathrm{N}$ et al. Iron, folic acid and vitamin $\mathrm{B} 12$ deficiencies related to anemia in adolescents from a region with a high incidence of congenital malformations in Venezuela. Arch Latinoam Nutr. 2005;55(2):118-123.

14. Singh V, Nigwekar P, Dhyabar A et al. Case Series of Megaloblastic Anemia due to Vitamin B12 Deficiency in Exclusively Breastfed Infants Born to Vegan Mothers in a Rural Area. Pravara Med Rev. 2015; 7(1):22-24.

15. Guez S, Chiarelli G, Menni F et al. Severe vitamin B12 deficiency in an exclusively breastfed 5-month-old Italian infant born to a mother receiving multivitamin supplementation during pregnancy. $B M C$ Pediatr. 2012;12:85.

16. Goraya JS, Kaur S, Mehra B. Neurology of Nutritional Vitamin B12 Deficiency in Infants: Case Series From India and Literature Review. J Child Neurol. 2015; 30(13):1831-1837.

17. Quentin C, Huybrechts S, Rozen L et al. Vitamin B12 deficiency in a 9-month-old boy. Eur J Pediatr. 2012; 171(1):193-195.

18. Chandra J. Megaloblastic anemia: Back in focus. Indian J Pediatr. 2010; 77(7):795-799.

19. Gomber S, Kela K, Dhingra N. Clinico-hematological profile of megaloblastic anemia. Indian Pediatr. 1998;35(1):55-58.

20. Yeruva SLH, Manchandani RP, Oneal P. Pernicious Anemia with Autoimmune Hemolytic Anemia: A Case Report and Literature Review. Case Rep Hematol. 2016; 2016:7231503.

21. Vucelić V, Stancić V, Ledinsky M et al. Combined megaloblastic and immunohemolytic anemia associated - a case report. Acta Clin Croat. 2008; 47(4):239-243.

22. Feld S, Landau Z, Gefel D et al. Pernicious anemia, Hashimoto's thyroiditis and Sjögren's in a woman with SLE and autoimmune hemolytic anemia. J Rheumatol. 1989;16(2):258-259.

23. Srinivas M, Ravali G. Rare presentation of Megaloblastic Anemia: A Case Report. IJSS Case Rep Rev. 2015;1(9):46-48.

Conflict of interest: none declared Financial support: none declared 